\title{
Information modeling of windows with the account of thermophysical characteristics
}

\author{
Elena Ignatova $^{1^{*}}$ \\ ${ }^{1}$ Moscow state university of civil engineering, Yaroslavskoye shosse, 26, Moscow, Russia, 129337
}

\begin{abstract}
The task of improving the buildings energy efficiency is one of the most important tasks in the design of buildings. The buildings energy efficiency can be improved by rational choice of building structures and reduction of the heat transfer. Significant heat transfer of a building occurs through the windows. At the design stage of a building, it is necessary to estimate the magnitude of a heat transfer of different windows. Currently the designers are increasingly using the technology of building information modeling (BIM). 3D-model of the building consists of models of structural elements, which contain information about the different geometric, physical, technological and other characteristics of the structure. The aim of this work is to develop a parametric information model of the window taking into account its heat transfer resistance. In this paper the design of window units with one, two and three sashes are discussed. The value of window-reduced resistance to a heat transfer is calculated inside the window information model and is presented in the table. The method can be applied to different window design. Thermophysical parameter of the window information model can be used to assess the energy costs of operating the building.
\end{abstract}

Keywords: energy efficiency, modeling, window, heat transfer

\section{Introduction}

The inflow, utilization and loss of energy are accounted when assessing the energy efficiency of the building. The part of the heat energy goes into the environment as a result of the energy transfer through the outer structure of the building. Significant heat transfer of the building occurs through the windows. To reduce a heat transfer we need to choose a rational design and materials of window construction. A window consists of a frame and several sashes. In turn, a sash consists of sash frames and glazing. Window manufacturers give background information about resistance to a heat transfer for various kind of their glazing and sash frames.

Window heat loss depends on the size and number of sashes, on fastening system of the sashes (Fig.1).

The estimation of the thermal characteristics of window at the design stage can reduce the heat loss of the building and increase its energy efficiency.

\footnotetext{
*Corresponding author: ignatova@mgsu.ru
} 


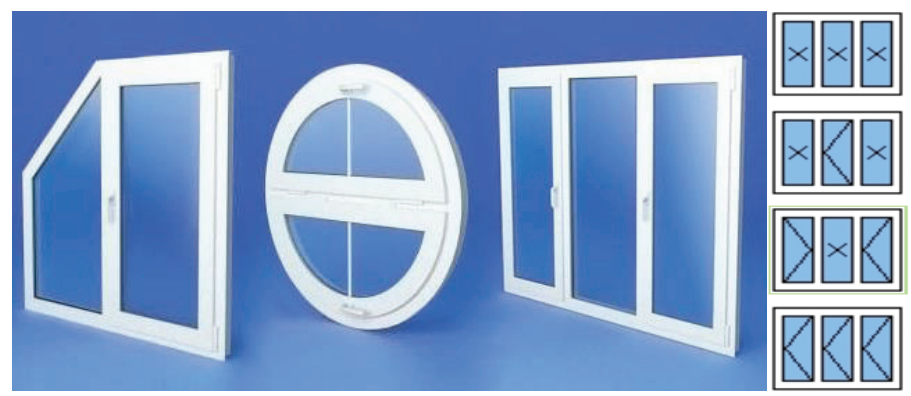

Fig 1. The examples of the window structures.

It is common in Russia to use resistance to a heat transfer $R\left(\mathrm{~m}^{2} \cdot{ }^{\circ} \mathrm{C} / \mathrm{W}\right)$ for evaluating of the thermal protective performance of structures. A window is a heterogeneous construction and consists of different materials.

The reduced resistance to a heat transfer of the whole window $R w\left(m^{2} \cdot{ }^{\circ} \mathrm{C} / \mathrm{W}\right)$ can be calculated using the following formula:

$$
R w=\frac{\sum_{i} F_{i}}{\sum_{i} \frac{F_{i}}{R_{i}}},
$$

where $F_{i}$ - area of the $i$-th uniform zone, $m^{2}$

$R_{i}$-resistance to a heat transfer of the $i$-th uniform zone, $m^{2} \cdot{ }^{\circ} \mathrm{C} / W$.

To calculate the window reduced resistance to a heat transfer $R w$, we need to know the area and the resistance to a heat transfer of each uniform area of the window. Tables of experimental data of the resistance to a heat transfer for different window structures are presented in GOST 23166-99 [1]. Minimum regulatory requirements for $R w$ are defined in GOST 26602.1-99 [2]. The actual window reduced a heat transfer resistance is determined as the result of certification tests. If the tests do not exist, we can analytically calculate window reduced resistance to a heat transfer.

The problem of evaluation of the building element's heat transfer was considered in the papers [3-5]. In paper [3] various measures to increase the given thermal resistance of the window unit are considered. The analysis value of the reduced resistance to a heat transfer for the window systems of different companies was performed. In paper [4] the dependence of resistance to a heat transfer of the window from the tilt angle, the size of the glazing, selective glass coating and the physical characteristics of the gas filling the space between glass panes were investigated. In paper [5] the effect of wind speed on the change of resistance to a heat transfer of translucent facade structures of tall buildings was investigated.

Analysis of the heat loss for various options of windows can be made by automatically. In paper [6] a methodology and program for calculating the heat loss through the wall with regard to windows was developed. In paper [7] the numerical study of the resistance to a heat transfer of walls with windows was held on the base of software Ansys.

Currently the designers of buildings are increasingly using the technology of building information modeling (BIM). 3D-model of the building consists of models of structural elements, which contain information about the different geometric, physical, technological and other characteristics of the structure. A building information model can serve as a basis for the analysis of the geometry, structure, strength, cost and other characteristics of the building object [8-11]. Technologies of the building information model analysis are described in [12]. Building information model can be used during all stages of the life cycle of construction object. 
The most common application of building information modeling is Autodesk Revit [13]. This program has the function of calculating the energy efficiency of a building based on its information model [14]. However, the calculation process is using the cloud service, and interim data calculation is not available. The main parameters of the Autodesk Revit basic window model are length, width, height and material. The basic window model may be useful only for the solution of simple problems of building design. However, Autodesk Revit allows to create new information models of building structures (called families) and allows to add the necessary parameters to them $[15,16]$.

\section{Materials and methods}

This work is based on the use of the theory of calculation of building heat loss and the theory of building information modeling with the help of Autodesk Revit.

The aim of this work is the creation of Revit information model of a window with automated calculation of the reduced resistance to a heat transfer that depends on the design of the window.

As a result of the research a parametric family of window models was developed. This information model may be used for evaluating the energy efficiency of the building.

Operations with the building information model in Autodesk Revit are based on the creation and application of parametric families of building structures elements $[15,16]$. For each element it is needed to create the parameters, to set their values and to define necessary relationships between the parameters. The relationship can be set by analytical expressions. The change of one parameter of the structural element will automatically cause the change of other related parameters. Thus, on the basis of a single parametric family the various options of design elements can be obtained.

Autodesk Revit allows to combine multiple simple families into more complex composite family. The construction of multi-sash window family is based on this principle.

In this study, it is assumed that the parent window family consists of the family of a frame and the families of sashes. In turn, the parametric family of the sash is composed of interconnected families of the glazing and the sash frame (Fig. 2). If the sash is fixed, then there is no sash frame.

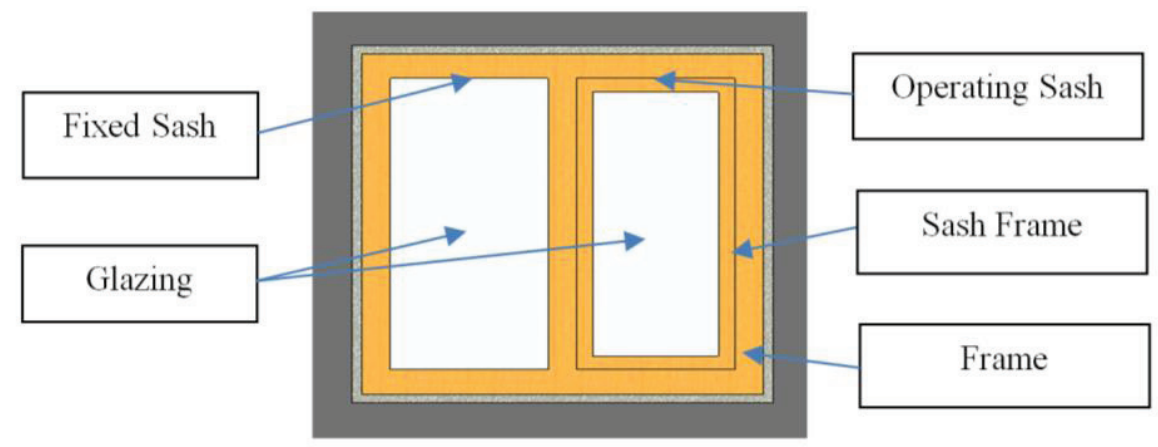

Fig. 2. The elements of the window.

Each family of the glazing or the sash frame has a variable parameter of the material. The parameter of the material includes graphic, strength, thermophysical characteristics, which can be used in $3 \mathrm{D}$ and $2 \mathrm{D}$ visualization of the window model. They also can be used to define other necessary characteristics of the family. Collections of glazing and frames were developed for window modelling. 
The glazing consists of a set of items, such as glass, spacer, desiccant, two sealants, filling gas (Fig. 3). Glazing can have a single glass, two or three glasses. Type and glass thickness conform to industry standards. The resistance to a heat transfer is obtained experimentally for all real types of glass. Therefore, the parameter of thermal resistance is specified numerically for each type of window families. The dimensions of the glazing are parametric and are associated with the size of the sash frame.
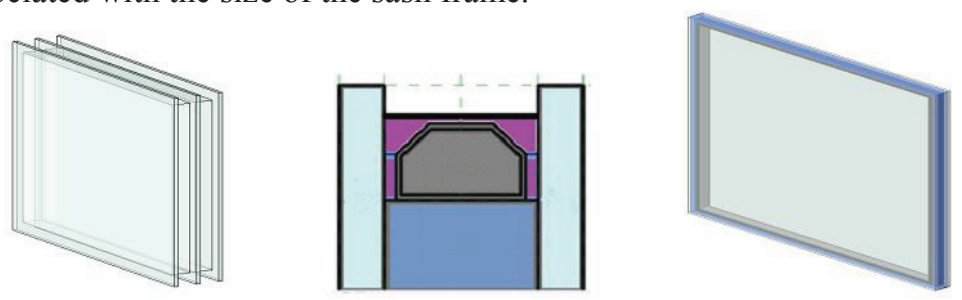

Fig. 3. The structure of glazing.

Plastic, metal and wood can be used as a material of the frames. There are many options of profiles of frames (Fig. 4).

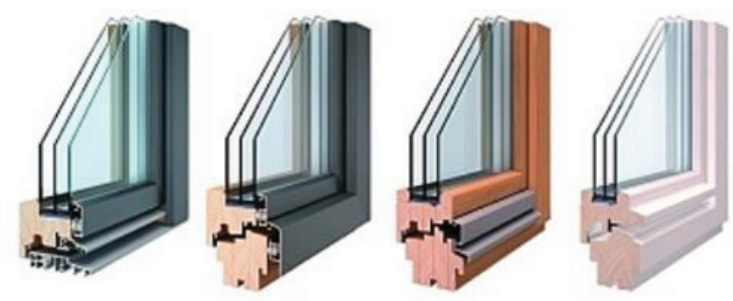

Fig 4. The variants of frames.

Reduced resistance to a heat transfer of the sash depends on the size of the sash. To be more accurate it depends on the area ratio between the glazing and the sash frame. For any size of the sash the calculation of the resistance to a heat transfer is carried out automatically. It is assumed that all sashes in one window have the same profiles of frames and the same glazing.

The reduced resistance to a heat transfer of an operating sash $R s\left(m^{2} \cdot{ }^{\circ} \mathrm{C} / \mathrm{W}\right)$ can be calculated by the formula:

where $S g$ - area of the glazing, $m^{2}$.

$$
R s=\frac{S g+S s f}{\frac{S g}{R g}+\frac{S s f}{R s f}},
$$

$R g$ - resistance to a heat transfer of the glazing, $m^{2} \cdot{ }^{\circ} \mathrm{C} / \mathrm{W}$.

$S s f$ - area of the sash frame, $m^{2}$;

Rsf-resistance to a heat transfer of the sash frame, $m^{2} \cdot{ }^{\circ} \mathrm{C} / \mathrm{W}$.

If the window family consists of a frame family and several sash families, the reduced resistance to a heat transfer $R w\left(m^{2} \cdot{ }^{\circ} \mathrm{C} / W\right)$ can be calculated by the formula:

where $S s_{i}$ - area of the $i$-th sash, $m^{2}$;

$$
R w=\frac{\sum_{i} S s_{i}+S f}{\sum_{i} \frac{S s_{i}}{R s_{i}}+\frac{S f}{R f}},
$$

$R s_{i}-$ reduced resistance to a heat transfer of the $i$-th sash, $m^{2} \cdot{ }^{\circ} \mathrm{C} / \mathrm{W}$;

$S f$-area of frame, $\mathrm{m}^{2}$; 


\section{$R f$ - resistance to a heat transfer of the frame, $m^{2} \cdot{ }^{\circ} \mathrm{C} / W$.}

The calculations take into account the structure, the proportions, the materials and thermophysical characteristics of nested families.

\section{Results}

The proposed method of window modeling and the calculation of its resistance to a heat transfer is based on the technology of building information modeling. Information model of the window was implemented for structures with one, two and three sashes (Fig.5).

Information model of the window allows to set the direction for opening the sashes. Accordingly, the location of the handle and the notation of sash opening are changed. If the fixed sash is selected, the glazing is inserted into the window frame. The size of the glass is parametrically associated with the dimensions of the sash frame. The dimensions of sash frame are parametrically associated with the size of the window frame.
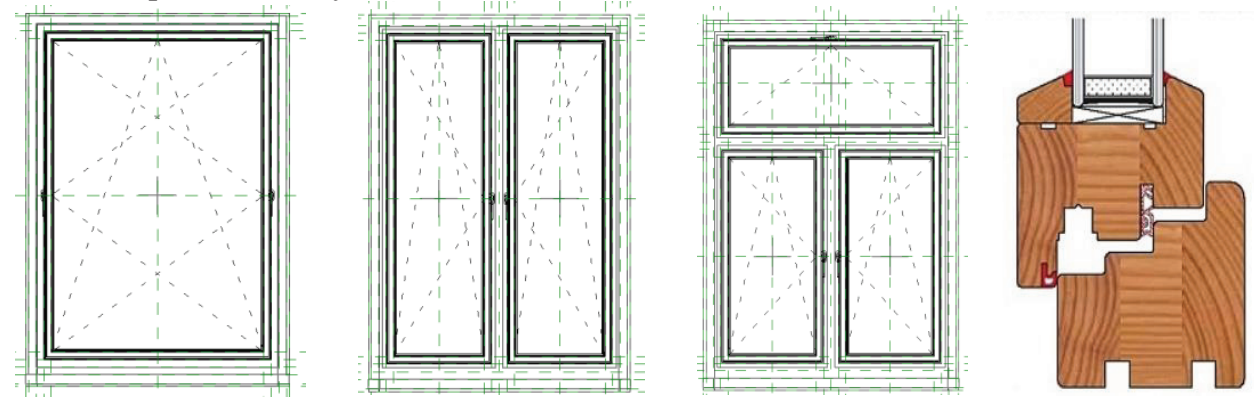

Fig. 5. Models of wood window with one, two and three sashes.

Table 1 shows the results of modelling of different wooden windows. The reduced resistance to a heat transfer $R w$ was compared with data $R o$ from [17] (if it is presented). The size of the window is $1400 \times 2000 \mathrm{~mm}$. The window has a fixed sash with double glazing. Frame design is FloraIV-78 Fir. The value of $R f$ equal to $0.71\left(\mathrm{~m}^{2} \cdot{ }^{\circ} \mathrm{C} / \mathrm{W}\right)$.

Table 1. Rw of different windows

\begin{tabular}{|c|c|c|c|c|}
\hline Number of Sashes & Glazing & $\boldsymbol{R g}$ & $\boldsymbol{R} \boldsymbol{w}$ & $\boldsymbol{R o}$ [17] \\
\hline 1 & 4M1-8-4M1 & 0.28 & 0.334 & 0.334 \\
\hline 1 & 4M1-Ar8-4M1 & 0.30 & 0.355 & 0.355 \\
\hline 2 & 4M1-8-4M1 & 0.28 & 0.325 & 0.326 \\
\hline 2 & 4M1-Ar8-4M1 & 0.30 & 0.347 & 0.347 \\
\hline 3 & 4M1-8-4M1 & 0.28 & 0.352 & - \\
\hline 3 & 4M1-Ar8-4M1 & 0.30 & 0.372 & - \\
\hline
\end{tabular}

During creation of the window models with one, two and three sashes, the issue of creating a single universal window family was discussed. The universal window family is the family that can be implemented in all these cases. However, a large number of conditions imposed on the model, and a large number of control parameters starts to hinder the work of the designer. 


\section{Conclusions}

The study deals with the problem of computing the heat loss through the windows to solve the problem of energy efficiency of the building.

The calculation of the reduced resistance to a heat transfer through the window is only the first step in determining the heat loss of a building when calculating its efficiency. For further calculations it is necessary to know the construction area and the climatic characteristics. Also for the design of the building it is necessary to know the minimum allowable values of thermal resistance of building structures.

Thermal insulation properties of the window are enhanced by reducing the area of glazing, by adding inert gases and by increasing the number of glasses. However, improving the thermal insulation properties of the window leads to a reduction in lighting. It is necessary to discuss two problems at the same time. The parameters for evaluating light transmission should be included in the information model of the window in the future.

The method of information modeling implemented on the base of the program of building information modeling Autodesk Revit. Hierarchy of Autodesk Revit families was established for organizing the composite family of the window. The relationships between geometric and thermophysical parameters of the families were determined. The automatic calculation of reduced resistance to a heat transfer of the entire window was organized in the composite family.

The methodology of creation of window information models with the evaluation of the thermophysical characteristics is versatile and can be used for different windows.

\section{References}

1. GOST 23166-99. Window structures (1999).

2. GOST 26602.1-99. Blocks of windows and doors. Methods of determining of the resistance to heat transfer (1999).

3. E. S. Konisheva, E. V. Korepanov. The methods of increasing the reduced resistance to a heat transfer of the window. The materials of regional scientifically practical seminar. Energy and resource saving in industry, housing and communal services and agriculture, 119-125 (2016).

4. E. V. Korepanov. Mathematical modeling of heat transfer through the exterior walls of buildings with windows.( Izhevsk, Kalashnikov Izhevsk State Technical University, 2011)

5. Y. A. Eldashov, S. G. Sesunin, V. N. Kovrov. Experimental study of the window frame model taking into account the geometric stability and reduced resistance to a heat transfer. Vestnik MGSU, 3, 146-149 (2009).

6. V. M. Tusnina, Tusnin A.R.Thermal resistance of walls with window openings. Vestnik MGSU, 1-2, 123-128 (2011).

7. S. S. Golubev. Determination of reduced resistance to a heat transfer of fencing wall based on numerical calculation of distribution of temperature fields, Scientific and Technical Volga region Bulletin, 5, 93-97 (2011).

8. V. V. Talapov. Basis of BIM: introduction to building information modeling. Moscow, (DMK Press, 2011).

9. E. V. Ignatova. Solution of problems on the base of building information models. Vestnik MGSU, Proceedings of Moscow State University of Civil Engineering, 9, 241-246 (2012).

10. E. V. Ignatova. The effective use of building information model. Abstracts of the 14th International Conference on Computing in Civil and Building Engineering Moscow. June 27-29, 132-133. (2012). 
11. E. Ignatova, H. Kirschke, E. Tauscher, K. Smarsly. Parametric geometric modeling in construction planning using industry foundation classes. Proceedings of the 20th International Conference on the Applications of Computer Science and Mathematics in Architecture and Civil Engineering. Weimar, 68-75. (2015).

12. E. V. Ignatova. Technologies of the building information model analysis. Advances in Energy Science and Equipment Engineering II, Taylor \& Francis Group, London, 653657 (2017)

13. NBS National BIM Report 2016. URL: https://www.thenbs.com/knowledge/nationalbim-report-2016.

14. Anergy for Autysis Revit. URL: https://knowledge.autodesk.com/support/revit-products/learnexplore/caas/CloudHelp/cloudhelp/2016/ENU/Revit-Analyze/files/GUIDA4C490A7-A86C-4027-B829-A77AB3211B60-htm.html

15. A. L. Lanzov. Autodesk Revit 2015. Computer aided design of buildings. (RIOR Press, 2014).

16. J. Vandezande, E. Krygiel Mastering Autodesk. Revit architecture 2016. (SYBEX, 2016).

17. Calculator of windows. URL: http://vbokna.ru/kalkulyatory/r-opr/ 